\title{
Corticosteroid therapy for sepsis: a clinical practice guideline
}

\author{
Francois Lamontagne, ${ }^{12}$ Bram Rochwerg, ${ }^{34}$ Lyubov Lytvyn, ${ }^{4}$ Gordon H Guyatt, ${ }^{4}$ \\ Morten Hylander Møller, ${ }^{5}$ Djillali Annane, ${ }^{6}$ Michelle E Kho, ${ }^{7}$ Neill KJ Adhikari, ${ }^{8} 9$ \\ Flavia Machado, ${ }^{10}{ }^{11}$ Per O Vandvik, ${ }^{12}{ }^{13}$ Peter Dodek, ${ }^{14}$ Rebecca Leboeuf, ${ }^{15}$ Matthias Briel, ${ }^{4} 16$ \\ Madiha Hashmi, ${ }^{17}$ Julie Camsooksai, ${ }^{18}$ Manu Shankar-Hari, ${ }^{19}{ }^{20}$ Mahder Kinfe Baraki, ${ }^{21}$ \\ Karie Fugate, ${ }^{22}$ Shunjie Chua, ${ }^{23}$ Christophe Marti, ${ }^{24}$ Dian Cohen, ${ }^{25}$ Edouard Botton, ${ }^{26}$ \\ Thomas Agoritsas, ${ }^{47}$ Reed A C Siemieniuk ${ }^{4}$
}

Full author details can be found at the end of the article

Correspondence to RACSiemieniuk

reed.siemieniuk@medportal.ca

Cite this as: BMJ 2018;362:k3284 doi: $10.1136 /$ bmj.k3284

This BMJ Rapid Recommendation article is one of a series that provides clinicians with trustworthy recommendations for potentially practice changing evidence. $B M /$ Rapid Recommendations represent a collaborative effort between the MAGIC group (http:// magicproject.org//) and The $B M J$. A summary is offered here and the full version including decision aids is on the MAGICapp (https://app.magicapp.org), for al devices in multilayered formats. Those reading and using these recommendations should consider individual patient circumstances, and theirvalues and preferences and may want to use consultation decision aids in MAGICapp to facilitate shared decision making with patients. We encourage adaptation and contextualisation of our recommendations to local or other contexts. Those considering use or adaptation of content may go to MAGICapp to link or extract its content or contact The BMJ for permission to reuse content in this article.
Do corticosteroids reduce death or improve recovery in people with sepsis or septic shock? Our panel make a weak recommendation to give corticosteroids to people with all types and severity of sepsis, based on new evidence. Because we are not certain that they are beneficial, it is also reasonable not to prescribe them. Patients' values and preferences may guide this decision-making process.

This rapid recommendation was triggered by two trials, with differing conclusions whose results might change practice:

- ADRENAL (3658 patients who had septic shock) found no statistically significant difference in $\mathbf{9 0}$ day mortality between the hydrocortisone and placebo groups. ${ }^{1}$

- APROCCHSS (1241 patients who had septic shock) found that hydrocortisone plus fludrocortisone reduced 90 day mortality. ${ }^{2}$

The trials are incorporated into a linked systematic review comparing corticosteroids with placebo. ${ }^{3}$ This BMJ Rapid Recommendation promptly and transparently translates this evidence using GRADE methodology for trustworthy guidelines. Sepsis is a life threatening organ dysfunction from infection. Currently most guidelines advise against

\section{WHAT YOU NEED TO KNOW}

- Sepsis is a syndrome of life threatening infection with organ dysfunction, and most guidelines do not advise use of corticosteroids to treat it in the absence of refractory shock

- Two new trials of corticosteroid treatment for sepsis came to differing conclusions

- Corticosteroids may reduce the risk of death by a small amount and increase neuromuscular weakness by a small amount, but the evidence is not definitive

- This guideline makes a weak recommendation for corticosteroids in patients with sepsis; both steroids and no steroids are reasonable management options

- Fully informed patients who value avoiding death over quality of life and function would likely choose corticosteroids giving corticosteroids in sepsis in the absence of refractory shock, but these guidelines have not taken into account the new evidence. We do not anticipate that new clinical trials will substantively alter the evidence suggesting a small but uncertain mortality reduction. The box below shows publications linked in this Rapid Recommendation package. The main infographic provides an overview of the absolute benefits and harms. The table at the end of the article shows any evidence that has emerged since the publication of this guideline.

\section{Current understanding}

Sepsis is life threatening organ dysfunction caused by a dysregulated host response to infection. ${ }^{4}$ In practice, a sepsis-related organ failure assessment (SOFA) score of $\geq 2$ in patients with infections is sepsis (table 1 ). ${ }^{45}$ Worldwide, about 30 million people are hospitalised with sepsis every year and up to six million of them die. ${ }^{6}$

Clinicians typically manage sepsis with early, broad spectrum antibiotics. They may provide supportive treatment such as vasoactive drugs and mechanical ventilation. They track and adjust treatment based on clinical signs and laboratory data. ${ }^{7}$ Septic shock is the most severe form of sepsis. These patients experience profound circulatory, metabolic, and cellular abnormalities. ${ }^{48}$ They require vasopressors to maintain perfusion pressure and have elevated serum lactate concentrations despite adequate fluid repletion.

Linked articles in the BMJ Rapid Recommendation cluster

- Lamontagne F, Rochwerg B, Lytvyn L, et al. Corticosteroid therapy for sepsis: a clinical practice guideline. $B M J$ 2018;362:k3284

Summary of the results from the Rapid

Recommendation process

- Rochwerg B, Oczkowski SJ, Siemieniuk RAC, et al. Corticosteroids in sepsis: an updated systematic review and meta-analysis. Crit Care Med 2018. doi:10.1097/ CCM. $0000000000003262^{3}$

- Review and meta-analysis of all available randomised trials that assessed corticosteroid therapy for sepsis

- MAGICapp (https://app.magicapp.org/public/guideline/ EZ1w8n)

Expanded version of the results with multilayered recommendations, evidence summaries, and decision aids for use on all devices 

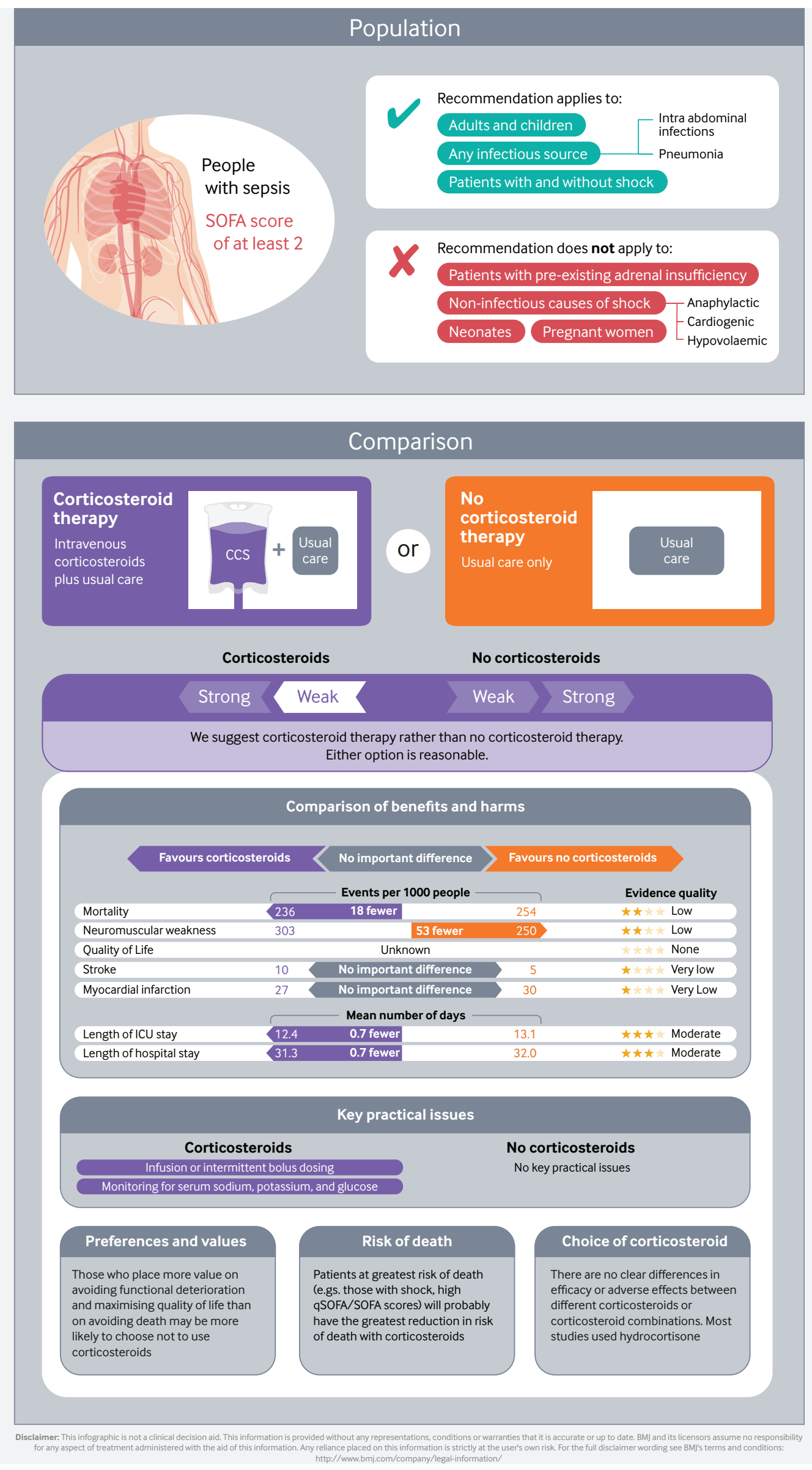


\begin{tabular}{|c|c|c|c|c|c|}
\hline \multirow{2}{*}{$\begin{array}{l}\text { System or organ and } \\
\text { measure }\end{array}$} & \multicolumn{5}{|c|}{ SOFA score } \\
\hline & 0 & 1 & 2 & 3 & 4 \\
\hline \multicolumn{6}{|l|}{ Respiratory: } \\
\hline $\mathrm{P}_{\mathrm{a}} \mathrm{O}_{2} / \mathrm{FiO}_{2}, \mathrm{~mm} \mathrm{Hg}$ & $\geq 400$ & 300-399 & $200-299$ & $\begin{array}{l}\text { 100-199 with } \\
\text { respiratory support }\end{array}$ & $\begin{array}{l}<100 \text { with } \\
\text { respiratory } \\
\text { support }\end{array}$ \\
\hline \multicolumn{6}{|l|}{ Coagulation: } \\
\hline Platelets, $\times 10^{3} / \mu \mathrm{L}$ & $\geq 150$ & 100-149 & 50-99 & $20-49$ & $<20$ \\
\hline \multicolumn{6}{|l|}{ Liver: } \\
\hline Bilirubin, $\mu \mathrm{mol} / \mathrm{L}(\mathrm{mg} / \mathrm{dL})$ & $<20(1.2)$ & $20-32(1.2-1.9)$ & 33-101 (2.0-5.9) & $102-204(6.0-11.9)$ & $>204(12.0)$ \\
\hline \multicolumn{6}{|l|}{ Circulatory: } \\
\hline $\begin{array}{l}\text { Mean arterial pressure, } \\
\mathrm{mmHg}\end{array}$ & $\geq 70$ & $<70$ & $\begin{array}{l}\text { Low dose } \\
\text { dopamine } \\
\text { or any dose } \\
\text { dobutamine }\end{array}$ & $\begin{array}{l}\text { Low-medium dose } \\
\text { noradrenalin or } \\
\text { adrenalin; medium } \\
\text { dose dopamine }\end{array}$ & $\begin{array}{l}\text { High dose } \\
\text { noradrenalin, } \\
\text { adrenalin, or } \\
\text { dopamine }\end{array}$ \\
\hline \multicolumn{6}{|l|}{ Central nervous system: } \\
\hline $\begin{array}{l}\text { Glasgow Coma Scale } \\
\text { score }\end{array}$ & 15 & $13-14$ & $10-12$ & $6-9$ & $<6$ \\
\hline \multicolumn{6}{|l|}{ Renal: } \\
\hline $\begin{array}{l}\text { Creatinine, } \mu \mathrm{mol} / \mathrm{L} \\
(\mathrm{mg} / \mathrm{dL})\end{array}$ & $\begin{array}{l}110 \\
(1.2) \\
\end{array}$ & $\begin{array}{l}110-170(1.2- \\
1.9)\end{array}$ & $\begin{array}{l}171-299(2.0- \\
3.4)\end{array}$ & $300-440(3.5-4.9)$ & $>440(5.0)$ \\
\hline Urine output, $\mathrm{mL} /$ day & - & - & - & $<500$ & $<200$ \\
\hline
\end{tabular}

\begin{tabular}{|c|c|c|c|}
\hline \multirow[b]{2}{*}{ Society } & \multicolumn{3}{|c|}{ Recommendation regarding corticosteroid use } \\
\hline & In sepsis & In septic shock & Other situations \\
\hline $\begin{array}{l}\text { "Surviving Sepsis" } \\
\text { for SCCM and } \\
\text { ESICM, } 2016^{7}\end{array}$ & Against & $\begin{array}{l}\text { In favour for hypotension } \\
\text { refractory to fluid resuscitation } \\
\text { and vasopressor }\end{array}$ & $\begin{array}{l}\text { History of adrenal insufficiency or } \\
\text { corticosteroid use }\end{array}$ \\
\hline $\begin{array}{l}\text { CIRCI guidelines } \\
\text { for SCCM and } \\
\text { ESICM, } 2018^{1213}\end{array}$ & Against & $\begin{array}{l}\text { In favour for shock not responsive } \\
\text { to fluid and at least moderate } \\
\text { dose vasopressor }\end{array}$ & $\begin{array}{l}\text { Acute respiratory distress syndrome } \\
\text { Community acquired pneumonia } \\
\text { Bacterial meningitis } \\
\text { History of adrenal insufficiency or } \\
\text { corticosteroid use }\end{array}$ \\
\hline CAEP, $2008^{14}$ & Against & $\begin{array}{l}\text { In favour for haemodynamically } \\
\text { unstable patients not responsive } \\
\text { to fluid resuscitation and } \\
\text { vasopressor }\end{array}$ & \\
\hline NICE, $2017^{15}$ & Not mentioned & Not mentioned & Not mentioned \\
\hline JSICM, $2018^{16}$ & Against & $\begin{array}{l}\text { In favour for shock not responsive } \\
\text { to initial fluid resuscitation and } \\
\text { vasoactive drugs }\end{array}$ & \\
\hline
\end{tabular}

It is possible that corticosteroids help improve the dysregulated immune response caused by sepsis ${ }^{9}$ and increase blood pressure if it is low. ${ }^{10}$ Some clinicians have found this biological rationale, and results of early studies, compelling. Others disagree and do not use corticosteroids. ${ }^{11}$

Most professional organisations recommend against corticosteroid use in the absence of refractory shock. ${ }^{12}$ Table 2 summarises current professional society guidelines.

\section{The evidence}

The linked systematic review identified 42 randomised controlled trials (RCTs) comparing corticosteroids with no corticosteroids (typically placebo). ${ }^{3}$ Figure 2 provides an overview of the trials and participants.

The systematic review includes total of 10194 patients who had sepsis. Of the 42 trials included, 24 restricted enrolment to patients who had septic shock. The typical patient was critically ill-a median of $32 \%$ of participants died within the first month. The most common sources of sepsis were pulmonary infections (median 44\%) and abdominal infections (median 17\%). Most of the RCTs used hydrocortisone alone ( $\mathrm{n}=26)$, others used hydrocortisone plus fludrocortisone $(\mathrm{n}=2)$, methylprednisolone $(n=6)$, prednisolone $(n=3)$, or dexamethasone $(n=3)$ (see fig 2). Although most of the clinical trials included patients who had septic shock, many included patients who did not (16 trials, 2241 patients). The linked systematic review provides detailed trial descriptions, including risk of bias assessments and patient characteristics. ${ }^{3}$

\section{Subgroups of patients}

Corticosteroids did not seem to be more or less effective in particular clinical subgroups, for example:

- Septic shock

- Pneumonia

- Acute respiratory distress syndrome (ARDS)

- Higher baseline risk of death

- Different corticosteroid drugs (such as hydrocortisone, methylprednisolone)

- Different corticosteroid doses

- Different corticosteroid regimens (such as single agents or corticosteroid combinations such as hydrocortisone plus fludrocortisone)

- More recent $v$ older trials

- Trials with higher $v$ lower risk of bias.

Older studies tended to use much higher doses of corticosteroids for a shorter time than are typically used now; the pooled evidence from these older studies is imprecise (few events), and the linked meta-analysis was underpowered to detect important subgroup differences such as by dose. All tests for relative subgroup effects may be underpowered to detect true differences because the effect sizes are small, especially for mortality. Therefore, we cannot be certain that a true subgroup effect does not exist. Future meta-analyses of individual patient data may help to identify populations that benefit more or less from corticosteroids. Until such time, we can only conclude that the evidence applies to all subgroups.

\section{Understanding the recommendation}

The main infographic provides an overview including the benefits and harms, and our certainty in the evidence for each outcome.

\section{Absolute benefits and harms}

There was better survival in the group taking corticosteroids, but this was not certain. This drives the weak rather than strong recommendation.

\section{Mortality}

Corticosteroids may reduce mortality in the first month after admission to an intensive care unit (ICU) by approximately $2 \%$. However, the panel had low certainty that this is true. The confidence interval crosses the line of no difference, and the results were inconsistent, with some RCTs showing a mortality reduction and others showing none. 
DATA SOURCES $\quad \begin{aligned} & \text { Use this information to gauge how } \\ & \text { similar your patients' conditions are }\end{aligned}$

to those of people studied in the trials

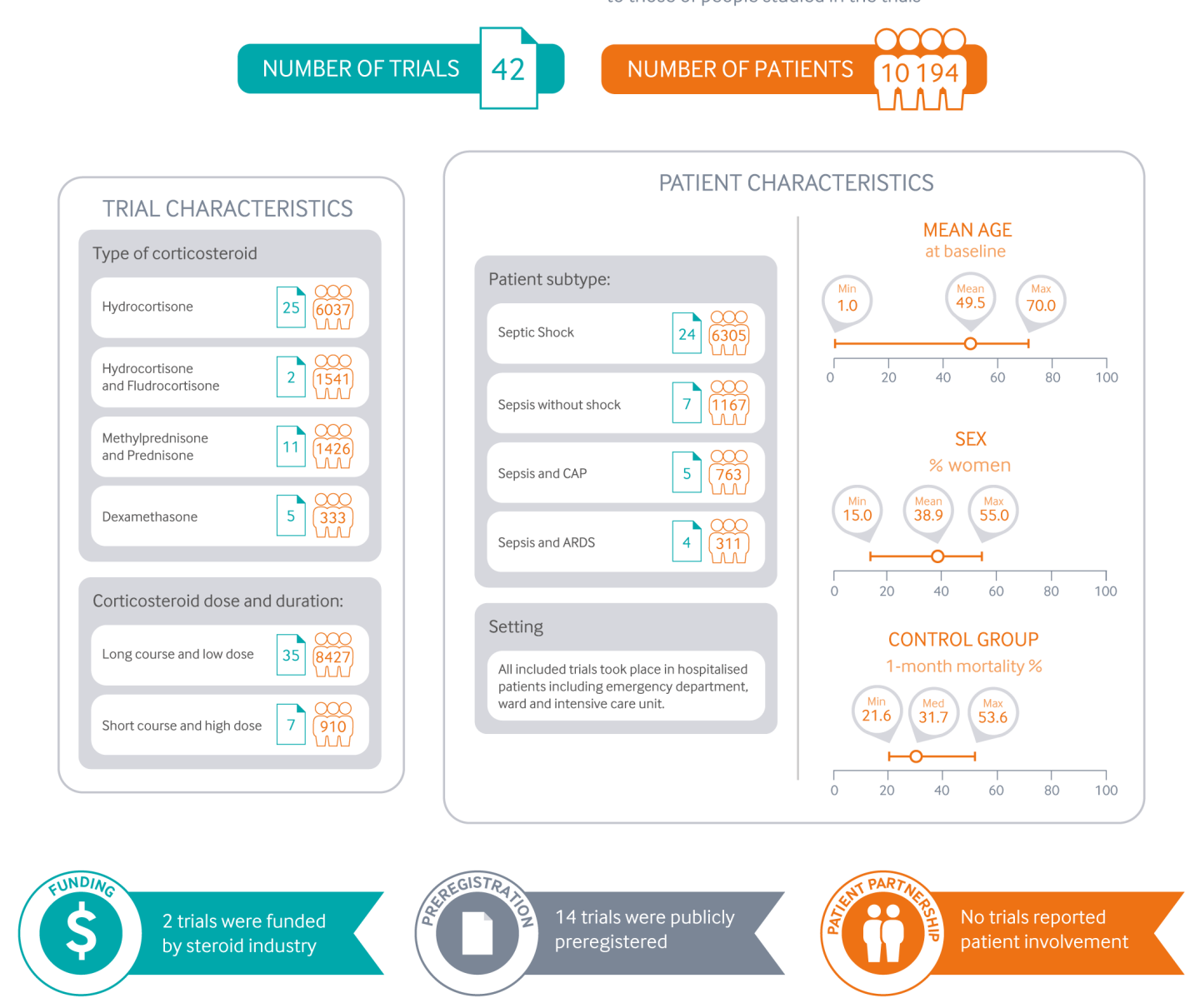

Fig 2 | Characteristics of patients and trials included in systematic review of the use of corticosteroids for treating sepsis ${ }^{3}$ $\mathrm{CAP}=$ community acquired pneumonia. $\mathrm{ARDS}=$ acute respiratory distress syndrome.

The effect on longer term mortality (from 60 days to 1 year) was similar. Fewer studies reported this outcome, so, although the results were consistent in the RCTs that did report this outcome, the panel also had low certainty that corticosteroids reduce longer term mortality.

\section{Quality of life}

No RCT reported quality of life outcomes at any time point. The ADRENAL study investigators are collecting quality of life data at six months, but these data have not been published. ${ }^{17}$

\section{Outcomes of some interest}

Corticosteroids may reduce the length of ICU and hospital stay by less than a day each (moderate quality evidence). The impact of corticosteroids on other patient-important outcomes such as stroke and myocardial infarction was extremely uncertain. They may increase the risk of neuromuscular weakness by a small amount (low quality evidence from seven RCTs). Possible explanations include the toxic effects on nerve and muscle cells, and hyperglycaemia from corticosteroid use. ${ }^{18}$ Weakness may compromise patients' ability to function independently ${ }^{19}$ and delay recovery. ${ }^{20}$

In two of the seven RCTs evaluating weakness, it was prospectively evaluated one month after enrolment. ${ }^{21}$
Evaluations of neuromuscular weakness, especially in RCTs that relied on investigator identification, were unreliable. The panel therefore believed that the RCTs probably underestimated the risk of neuromuscular weakness.

Outcomes of less importance

Corticosteroids probably increase the risk of hyperglycaemia and hypernatraemia. Corticosteroids probably improve organ function at day 7 and the chance of shock reversal at day 7 .

\section{Patient subgroups}

Our recommendation applies to all patients with sepsis. There was no meaningful difference in the efficacy of corticosteroids in different groups of patients including those with septic shock, pneumonia, acute respiratory distress syndrome, or other sources of sepsis, or those who were sicker. However, the absolute reduction in mortality from corticosteroids will be greater in patients with a higher risk of death. The absolute harm (such as neuromuscular weakness) will also be greater in sicker patients.

The analysis of a subgroup effect showed no convincing evidence of such an effect. Based on published criteria for credible subgroup effects, ${ }^{22}$ in the absence of a subgroup 


\section{HOW THIS RECOMMENDATION WAS CREATED}

Our international panel included sepsis survivors, family caregivers of patients who had sepsis, intensivists, internists, nurses, an endocrinologist, physiotherapists, trialists, and methodologists (see appendix 1 on bmj.com). They decided on the scope of the recommendation and the outcomes that are most important to patients. The panel judged death and quality of life to be the most important outcomes. Myocardia infarction, stroke, duration of stay in hospital and in the intensive care unit (ICU), superinfections, and neuromuscular weakness (such as ICU-acquired weakness) were also identified as important outcomes for patients.

Surrogate outcomes such as time to shock reversal, organ dysfunction measured by the sepsis-related organ failure assessment (SOFA) score, hyperglycaemia, and hypernatraemia were less important to the panel. This view is consistent with GRADE recommendations to focus on patient-important outcomes rather than surrogates. ${ }^{29}$

Subgroups of interest-The panel wanted to know whether the effect of corticosteroids differed in people with sepsis, compared with people who had septic shock, pneumonia, acute respiratory distress syndrome, or were at higher risk of death. ${ }^{30}$ They also wanted to know whether the type of corticosteroid or its dose influenced outcomes.

The panel met by videoconference to discuss the evidence and formulate a recommendation. No panel member had financial conflicts of interest; intellectual and professional conflicts were minimised and managed (see appendix 2 on bmj.com).

The panel requested a systematic review of randomised controlled trials on the impact of corticosteroid therapy for patients who have sepsis, including those who have septic shock. ${ }^{3}$ This review examines the two latest, as well as previous studies, on corticosteroids in sepsis. The aim was to resolve apparently conflicting evidence.

The panel followed the BMJ Rapid Recommendations procedures for creating a trustworthy recommendation, ${ }^{31}$ including using the GRADE approach to critically appraise the evidence and create recommendations (see appendix 3 on bmj.com). ${ }^{32}$ The panel considered the balance of benefits, harms, and burdens of corticosteroids, the quality of the evidence for each outcome, expected variations in patient values and preferences, and acceptability of corticosteroids. ${ }^{33}$ Determining patient values and preferences occurred before the panel received the results of the meta-analysis to reduce the risk that opinions regarding outcome importance will be data driven. According to the GRADE approach, recommendations can be strong or weak and for or against a course of action. ${ }^{33}$ High quality evidence of an effect on surrogate outcomes do not trigger strong recommendations.

effect, the interpretation of the effect of corticosteroids in any particular subgroup should be guided by the effect in the overall population of septic patients.

Several trials of corticosteroids for pneumonia or acute respiratory distress syndrome have enrolled patients who did not have sepsis; we did not consider these trials. Therefore, clinicians treating these conditions should also consider evidence ${ }^{2324}$ and guidelines ${ }^{12}$ applicable to patients who have pneumonia and acute respiratory distress syndrome.

\section{Patient values and preferences}

Fully informed patients who place a higher value on avoiding death than on quality of life and function would be more likely to choose to receive corticosteroids. We heard from our patient partners that most patients will want to reduce their risk of death, even if this reduction is small and uncertain. This view is consistent with the experiences of the rest of the panel. Most patients will likely be willing to accept a small increased risk of weakness.

Patients (or their care givers and surrogate decisionmakers) will probably vary in how they would weigh the balance of expected desirable and undesirable consequences from corticosteroids. We assume that most patients want to avoid death and will value even a small, uncertain reduction in mortality. We judge that they will be less concerned about the possible increase in weakness among survivors. There is also likely to be a sizeable minority of patients who would place a large value on avoiding a very uncertain but possible decline in quality of life and functional abilities even at the cost of a small increase in risk of death. ${ }^{25}$ Shared decision making conversations about specific interventions in patients with sepsis may not always be feasible, and could delay care. However, clinicians should do their best to elicit each patient's values and preferences. For example, they could talk about the patient's goals of care with the patient, their family, and friends.

\section{Practical considerations}

Figure 3 outlines the key practical issues for patients and clinicians discussing corticosteroid treatment for sepsis.

The optimal corticosteroid drug, dose, and duration of treatment are uncertain. Hydrocortisone was the most commonly used corticosteroid in the RCTs and is therefore a reasonable choice. Differences among corticosteroids, if they do exist, are probably small; dexamethasone, methylprednisolone, and prednisolone were also studied and produced similar results. Adding an agent that has additional mineralocorticoid activity, such as fludrocortisone, could be helpful, but that is highly speculative.

The typical hydrocortisone dose for an adult in the RCTs was 200-300 mg/day, given either as an infusion or as boluses every six hours. ${ }^{26}$ If an infusion is chosen, a bolus of 50-100 mg can be given before the infusion. In the RCTs the duration of treatment was typically 7-14 days, or less for those who were rapidly improving.

Inflammation may recur after discontinuing corticosteroid therapy, ${ }^{27}$ especially when it is stopped abruptly. ${ }^{28}$ Clinicians should carefully monitor all patients after discontinuing corticosteroids. In patients who deteriorate after stopping corticosteroids (such as development of shock or need for mechanical ventilation), reinitiating corticosteroid therapy could be helpful, although this is highly speculative. Whether corticosteroids should be tapered rather than stopped abruptly is unclear. Corticosteroid induced adrenal suppression is probably duration dependent, and so patients who receive longer courses of corticosteroids (such as $>14$ days) might be particularly likely to benefit from a taper before discontinuing and an evaluation of hypothalamo-pituitary-adrenal axis function if in doubt. ${ }^{12}$ 


\section{PRACTICAL ISSUES}

\begin{tabular}{|c|c|c|}
\hline & Corticosteroids & No corticosteroids \\
\hline \multirow{3}{*}{$\begin{array}{l}\text { MEDICATION } \\
\text { ROUTINE }\end{array}$} & Infusion or intermittent bolus dosing & \\
\hline & $\begin{array}{l}\text { Intravenous dosing initially; can change to } \\
\text { oral dosing when stable }\end{array}$ & \\
\hline & $\begin{array}{l}\text { May require short or long tapering doses } \\
\text { before stopping }\end{array}$ & \\
\hline & $\begin{array}{l}\text { Monitor and treat hyperglycaemia, } \\
\text { hypernatraemia, and hypokalaemia }\end{array}$ & $\begin{array}{l}\text { Routine sepsis monitoring including } \\
\text { bloodwork }\end{array}$ \\
\hline & $\begin{array}{l}\text { Monitor for recurrence of inflammation } \\
\text { and signs of adrenal insufficiency after } \\
\text { stopping corticosteroids }\end{array}$ & \\
\hline & $\begin{array}{l}\text { Routine sepsis monitoring including } \\
\text { bloodwork }\end{array}$ & \\
\hline \multicolumn{3}{|l|}{ CY } \\
\hline $\begin{array}{l}\text { EMOTIONAL } \\
\text { WELL-BEING }\end{array}$ & $\begin{array}{l}\text { Can cause insomnia and lead to psychiatric } \\
\text { adverse effects in some people, including } \\
\text { mania and psychosis in some predisposed } \\
\text { individuals }\end{array}$ & \\
\hline & Inexpensive, widely available & \\
\hline $\begin{array}{l}\text { COSTS \& } \\
\text { ACCESS }\end{array}$ & $\begin{array}{l}\text { The corticosteroid drugs evaluated in RCTs } \\
\text { are all considered essential medications by } \\
\text { the World Health Organization }\end{array}$ & \\
\hline \multirow{2}{*}{$\begin{array}{l}\text { } \bigcirc ९ \\
\text { FOOD } \\
\& D R I N K\end{array}$} & Can be given with or without food & \\
\hline & $\begin{array}{l}\text { When taken orally, corticosteroids should } \\
\text { be taken with food when possible }\end{array}$ & \\
\hline & Consider early physical therapy & Consider early physical therapy \\
\hline ERY & & \\
\hline
\end{tabular}

Fig 3| Practical issues about use of corticosteroids for treatment of sepsis

\section{Costs}

Corticosteroids are typically inexpensive and widely available. The impact of corticosteroids on the overall costs to patients and to health systems is uncertain and would be driven mostly by ICU and hospital lengths of stay or prolonged periods of rehabilitation.
Future research

With the exception of the awaited analysis of quality of life in the ADRENAL trial, there are currently no planned or ongoing RCTs in patients who have sepsis that are likely to substantively change the overall effect estimates for the key outcomes. Given remaining uncertainty regarding the 


\begin{tabular}{l}
\hline New evidence which has emerged after initial publication \\
Date New evidence Citation $\quad$ Findings Implications for recommendation(s) \\
There are currently no updates to the article. \\
\hline
\end{tabular}

effect of corticosteroids in different subgroups, additional analyses of existing data to explore heterogeneity of treatment effects are logical next steps before more patients are enrolled in similar trials. Such work mandates individual patient-data meta-analyses that rely on investigators sharing the data from their RCTs and cooperation among research networks.

It is possible that additional adaptive RCTs could help to resolve remaining uncertainty. Key research questions to inform decision makers and future guidelines are:

- What is the impact of corticosteroid therapy on quality of life in the short and long term?

- What is the impact of corticosteroid therapy on functional recovery?

- What is the impact of corticosteroid therapy on healthcare costs?

- Are there subgroups of patients with sepsis who benefit more or less from corticosteroid therapy?

- Are there differences between bolus and infusion dosing?

- Does the addition of fludrocortisone improve outcomes?

\section{Updates to this article}

The final table shows evidence that has emerged since the publication of this article. As new evidence is published, a group will assess the new evidence and make a judgment on to what extent it is expected to alter the recommendation.

Competing interests: All authors have completed the BMJ Rapid Recommendations interests disclosure form, and a detailed description of all disclosures is reported in appendix 2 on bmj.com. As with all BMJ Rapid Recommendations, the executive team and The BM/judged that no panel member had any financial conflict of interest. Professional and academic interests are minimised as much as possible, while maintaining necessary expertise on the panel to make fully informed decisions.

Funding: This guideline was not funded.

Transparency: R A C Siemieniuk affirms that the manuscript is an honest, accurate, and transparent account of the recommendation being reported that no important aspects of the recommendation have been omitted; and that any discrepancies from the recommendation as planned (and, if relevant, registered) have been explained.

1 Venkatesh B, Finfer S, Cohen J, et al. ADRENAL Trial Investigators and the Australian-New Zealand Intensive Care Society Clinical Trials Group. Adjunctive glucocorticoid therapy in patients with septic shock. N Engl/ Med 2018;378:797-808. 10.1056/NEJMoa1705835 pmid:29347874.

2 Annane D, RenaultA, Brun-Buisson C, et al. CRICS-TRIGGERSEP Network Hydrocortisone plus fludrocortisone for adults with septic shock. NEnglJ Med 2018:378:809-18.10.1056/NEJMoa1705716 pmid:29490185.

3 Rochwerg B, Oczkowski SJ, Siemieniuk RAC, et al. Corticosteroids in sepsis: an updated systematic review and meta-analysis. Crit Care Med 2018. 10.1097 CCM.0000000000003262 pmid:29979221.

4 Singer M, Deutschman CS, Seymour CW, et al. The third international consensus definitions for sepsis and septic shock (Sepsis-3). JAMA 2016;315:801-10. 10.1001/jama.2016.0287 pmid:26903338.

5 Vincent JL, Moreno R, Takala J, et al. The SOFA (Sepsis-related Organ Failure Assessment) score to describe organ dysfunction/failure. On behalf of the Working Group on Sepsis-Related Problems of the European Society of Intensive Care Medicine. Intensive Care Med 1996;22:707-10.10.1007 BF01709751 pmid:8844239.

6 Fleischmann C, Scherag A, Adhikari NK, et al. International Forum of Acute Care Trialists. Assessment of global incidence and mortality of hospitaltreated sepsis. Current estimates and limitations. Am J Respir CritCare Med 2016;193:259-72. 10.1164/rccm.201504-07810C pmid:26414292.

7 Rhodes A, Evans LE, Alhazzani W, et al. Surviving Sepsis campaign: international guidelines for management of sepsis and septic shock: 2016. Intensive Care Med 2017;43:304-77. 10.1007/s00134-017 4683-6 pmid:28101605.
8 Shankar-Hari M, Phillips GS, Levy ML, et al. Sepsis Definitions Task Force. Developing a new definition and assessing new clinical criteria for septic shock: for the third international consensus definitions for sepsis and septic shock (Sepsis-3). JAMA 2016;315:775-87. 10.1001/ jama.2016.0289 pmid:26903336.

9 Franchimont D, Kino T, Galon J, Meduri GU, Chrousos G. Glucocorticoids and inflammation revisited: the state of the art. NIH clinical staff conference. Neuroimmunomodulation 2002-2003;10:247-60. . 10.1159/000069969 pmid:12759562.

10 Hylands M, Moller MH, Asfar P, et al. A systematic review of vasopressor blood pressure targets in critically ill adults with hypotension. Can J Anaesth 2017;64:703-15. 10.1007/s12630-017-08771 pmid:28497426

11 Bruno IJ, Dee BM, Anderegg BA, Hernandez M, Pravinkumar SE. US practitioner opinions and prescribing practices regarding corticosteroid therapy for severe sepsis and septic shock. / Crit Care 2012;27:351-61 10.1016/j.jcrc.2011.12.011 pmid:22341726.

12 Annane D, Pastores SM, Rochwerg B, et al. Guidelines for the diagnosis and management of critical illness-related corticosteroid insufficiency (CIRCI) in critically ill patients (part I): Society of Critical Care Medicine (SCCM) and European Society of Intensive Care Medicine (ESICM) 2017 Intensive Care Med 2017;43:1751-63. 10.1007/s00134-017-49195 pmid:28940011.

13 Pastores SM, Annane D, Rochwerg B. Corticosteroid Guideline Task Force of SCCM and ESICM. Guidelines for the diagnosis and management of critical illness-related corticosteroid insufficiency (CIRCI) in critically ill patients (part II): Society of Critical Care Medicine (SCCM) and European Society of Intensive Care Medicine (ESICM) 2017. Crit Care Med 2018;46:146-8. 10.1097/ CCM.0000000000002840 pmid:29095205.

14 Green RS, Djogovic D, Gray S, et al. CAEP Critical Care Interest Group. Canadian Association of Emergency Physicians Sepsis Guidelines: the optimal management of severe sepsis in Canadian emergency departments. CJEM 2008;10:443-59.10.1017/ S148180350001054X pmid:18826733.

15 Tavaré A, O'Flynn N. Recognition, diagnosis, and early management of sepsis: NICE guideline. Br J Gen Pract 2017;67:185-6. 10.3399/ bjgp17X690401 pmid:28360070.

16 Nishida O, Ogura H, Egi M, et al. The Japanese Clinical Practice Guidelines for Management of Sepsis and Septic Shock 2016 (J-SSCG 2016). I Intensive Care 2018;6:7. 10.1186/s40560-017-02708 pmid:29435330.

17 Venkatesh B, Myburgh J, Finfer S, et al. ANZICS CTG investigators. The ADRENAL study protocol: adjunctive corticosteroid treatment in critically ill patients with septic shock. Crit Care Resusc 2013;15:83 8.pmid:23931038.

18 Wilcox SR. Corticosteroids and neuromuscular blockers in development of critical illness neuromuscular abnormalities: A historical review. J Crit Care 2017;37:149-55. 10.1016/j.jcrc.2016.09.018 pmid:27736708.

19 Schweickert WD, Pohlman MC, Pohlman AS, et al. Early physical and occupational therapy in mechanically ventilated, critically ill patients: a randomised controlled trial Lancet 2009:373:1874-82.10.1016/ S0140-6736(09)60658-9 pmid:19446324.

20 Herridge MS, Chu LM, Matte A, et al. RECOVER Program Investigators (Phase 1: towards RECOVER) Canadian Critical Care Trials Group. The RECOVER Program: disability risk groups and 1-year outcome after 7 or more days of mechanical ventilation. Am / Respir Crit Care Med 2016;194:831-44. 10.1164/rccm.201512-23430C pmid:26974173.

21 Keh D, Trips E, Marx G, et al. SepNet-Critical Care Trials Group. Effect of hydrocortisone on development of shock among patients with severe sepsis: the HYPRESS randomized clinical trial. JAMA 2016;316:1775-85. 10.1001/jama.2016.14799 pmid:27695824

22 Sun X, loannidis IP, Agoritsas T, Alba AC, Guyatt G. How to use a subgroup analysis: users' guide to the medical literature. JAMA 2014;311:405-11. 10.1001/jama.2013.285063 pmid:24449319.

23 Siemieniuk RA, Meade MO, Alonso-Coello P, et al. Corticosteroid therapy for patients hospitalized with community-acquired pneumonia: a systematic review and meta-analysis. Ann Intern Med 2015:163:519-28. 10.7326/M15-0715 pmid:26258555.

24 Meduri GU, Bridges L, Shih MC, Marik PE, Siemieniuk RAC, Kocak M. Prolonged glucocorticoid treatment is associated with improved ARDS outcomes: analysis of individual patients' data from four randomized trials and trial-level meta-analysis of the updated literature. Intensive Care Med 2016;42:829-40. 10.1007/s00134-015-40954 pmid:26508525.

25 Lamontagne F, Cohen D, Herridge M. Understanding patient-centredness: contrasting expert versus patient perspectives on vasopressor therapy for shock. Intensive Care Med 2017;43:1052-4. 10.1007/s00134-0164518-x pmid:27624068

26 Loisa P, Parviainen I, Tenhunen J, Hovilehto S, Ruokonen E. Effect of mode of hydrocortisone administration on glycemic control in patients with septic shock: a prospective randomized trial. Crit Care 2007;11:R21. 10.1186/cc5696 pmid:17306016.

27 Briel M, Spoorenberg SMC, Snijders D, et al. Ovidius Study Group Capisce Study Group STEP Study Group. Corticosteroids in patients hospitalized with community-acquired pneumonia: systematic review and individual patient data metaanalysis. Clin Infect Dis 2018;66:346-54. 10.1093/ cid/cix801 pmid:29020323. 
28 Meduri GU, Bridges L, Siemieniuk RAC, Kocak M. An exploratory reanalysis of the randomized trial on efficacy of corticosteroids as rescue therapy for the late phase of acute respiratory distress syndrome. Crit Care Med 2018;46:884-91. . 10.1097/ CCM.0000000000003021 pmid:29432350

29 Guyatt GH, Oxman AD, Santesso N, et al. GRADE guidelines: 12 Preparing summary of findings tables-binary outcomes. J Clin Epidemiol 2013;66:158-72. 10.1016/j.jclinepi.2012.01.012 pmid:22609141.

30 Rochwerg B, Oczkowski S, Siemieniuk RA et al Corticosteroids in sepsis: an updated systematic review and meta-analysis (protocol). BMJ Open 2017;7:e016847. 10.1136/bmjopen-2017-016847 pmid:28667229.

31 Siemieniuk RA, Agoritsas T, Macdonald H, Guyatt GH, Brandt L, Vandvik PO. Introduction to BMJ Rapid Recommendations. BMJ 2016;354:15191. 10.1136/bmj.i5191 pmid:27680768

32 Guyatt GH, Oxman AD, Vist GE, et al. GRADE Working Group. GRADE: an emerging consensus on rating quality of evidence and strength of recommendations. BM/ 2008;336:924-6.10.1136/ bmj.39489.470347.AD pmid:18436948.

33 Andrews IC, Schünemann HJ, Oxman AD, et al GRADE guidelines: 15. Going from evidence to recommendation-determinants of a recommendation's direction and strength. J Clin Epidemiol 2013;66:72635. 10.1016/j.jclinepi.2013.02.003 pmid:23570745.

Published by the BMJ Publishing Group Limited. For permission to use (where not already granted under a licence) please go to http://group. bmj.com/group/rights-licensing/permissions

This is an Open Access article distributed in accordance with the Creative Commons Attribution Non Commercial (CC BY-NC 4.0) license, which permits others to distribute, remix, adapt, build upon this work non-commercially, and license their derivative works on different terms, provided the original work is properly cited and the use is noncommercial. See: http://creativecommons.org/licenses/by-nc/4.0/
${ }^{1}$ Department of Medicine, Université de Sherbrooke, Sherbrooke, Canada ${ }^{2}$ Centre de recherche du CHU de Sherbrooke, Centre intégré universitaire de santé et de services sociaux - Estrie, Sherbrooke, Canada

${ }^{3}$ Department of Medicine, McMaster University, Hamilton, Canada

${ }^{4}$ Department of Health Research Methods, Evidence and Impact, McMaster University, Hamilton, Ontario, Canada

${ }^{5}$ Department of Intensive Care, Copenhagen University Hospital

Rigshospitalet, Copenhagen, Denmark

${ }^{6}$ Service de Médecine Intensive et Réanimation, Hôpital Raymond Poincaré, Garches, France

${ }^{7}$ School of Rehabilitation Science, McMaster University, Hamilton, Canada

${ }^{8}$ Department of Critical Care Medicine, Sunnybrook Health Sciences Centre, Toronto Canada

${ }^{9}$ Interdepartmental Division of Critical Care Medicine, University of Toronto, Toronto, Canada

${ }^{10}$ Federal University of Sao Paulo, Sao Paulo, Brazil

${ }^{11}$ Latin America Sepsis Institute, Sao Paulo, Brazil

${ }^{12}$ Institute of Health and Society, Faculty of Medicine, University of Oslo, Oslo, Norway

${ }^{13}$ Department of Medicine, Innlandet Hospital Trust-division, Gjøvik, Norway

${ }^{14} \mathrm{Center}$ for Health Evaluation and Outcome Sciences and Division of

Critical Care Medicine, St Paul's Hospital and University of British Columbia,

Vancouver, Canada

${ }^{15}$ Department of Medicine, Centre Hospitalier de l'Université de Montréal, Montréal, Canada

${ }^{16}$ Basel Institute for Clinical Epidemiology and Biostatistics, Department of Clinical Research, University Hospital Basel, University of Basel, Basel, Switzerland

${ }^{17}$ Department of Anaesthesiology, Aga Khan University, Karachi, Pakistan

${ }^{18}$ Poole Hospital NHS Foundation Trust, Dorset, United Kingdom

${ }^{19}$ Guy's and St Thomas' NHS Foundation Trust, London, United Kingdom

${ }^{20} \mathrm{NIHR}$ Clinician Scientist, School of Immunology \& Microbial Sciences, Kings College London, United Kingdom

${ }^{21}$ Department of Anesthesiology, Addis Ababa University, Addis Ababa, Ethiopia

${ }^{22}$ Renton, USA

${ }^{23}$ Carevise Mexico, Mexico City, Mexico

${ }^{24}$ Division of General Internal Medicine, Rehabilitation and Geriatrics, University Hospitals of Geneva, Geneva, Switzerland

${ }^{25}$ Centre de santé de la vallée Massawippi, Ayer’s Cliff, Canada

${ }^{26}$ Comité stratégique patient-partenaire, Centre de recherche du CHU de Sherbrooke, Centre intégré universitaire de santé et de services sociauxEstrie, Sherbrooke, Canada

${ }^{27}$ Division General Internal Medicine \& Division of Clinical Epidemiology, University Hospitals of Geneva, Geneva, Switzerland 